Case report

\title{
Laryngeal paraganglioma
}

\author{
Balasubramaniam A. ${ }^{1}$, Thirumaran B. ${ }^{2}$ \\ 1. Senior Registrar, ENT Surgery, Teaching Hospital, Jaffna, Sri Lanka \\ 2. Consultant Ent Surgeon, Teaching Hospital , Jaffna, Sri Lanka.
}

\begin{abstract}
:
Paragangliomas of the head and neck are rare especially in larynx. A 36 year old female patient presented with a history of progressive voice change and difficulty of swallowing for 6 months. During endoscopic examinationsmooth surfaced mass on Left supraglottic region, was noted. Tumour was excised through transcervical excision. Histology and immunohistochemistry of the tumour revealed that, it was paraganglioma.
\end{abstract}

Key words:paragangliomas, larynx

Copyright: (c) 2022 Balasubramaniam A, Thirumaran B.

This is an open access article distributed under the Creative Commons Attribution License (CC BY 4.0) CC) (7) This license lets others distribute, remix, tweak, and build upon the work, even commercially, as long as they credit the original author for the creation.

Funding: None

Competing interest: None

Correspondence:Dr. A. Balasubramaniam (abarnnab@gmail.com)

Accepted Date: $23^{\text {rd }}$ Jan 2022

Published Date: $26^{\text {th }}$ February 2022 


\section{Introduction}

Paragangliomas(PGLs) are neoplasms of neural crest origin.PGLs are rare in head and neck region.Even thoughdifficult to estimate the exact incidence of head and neck PGLs, they represent $<0.5 \%$ of all head and neck tumours. They couldbe originated from the carotid body, tympanic, jugular or vagal paraganglia ${ }^{1}$.

\section{Case report}

A 36-year-old female patient presented to the local hospital with a history of progressive voice change for 6 months. It was associated with difficulty of swallowing, butshe did not have shortness of breath or throat pain. A smooth surfaced mass on Left supraglottic region, which was obscuring the visualization of the true vocal fold was noticed during endoscopic examination (Fig: 1).CT scan revealed avidly enhancing mass lesion (size $1.3 \times 1.7 \times 2.4 \mathrm{~cm}$ )in the left side of the larynx , located between the epiglottis and vocal cord. Microlaryngoscopy andbiopsy were abandoned as tumour was vascular with a potential to bleed. TheCondition was explained to the patient. The tumour was excised through transcervical excision and laterallaryngotomy. Patient had an uneventful recovery and relieved of her problems. Histology and immunohistochemistry of the tumour revealed that, it was paraganglioma.

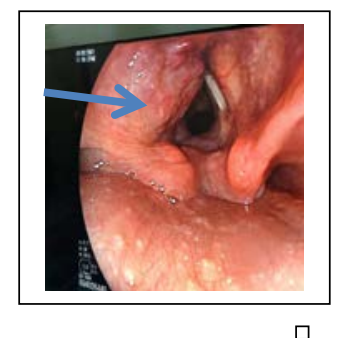

Figure 1: Arrow showing smooth left sided supraglottic mass

\section{Discussion}

PGLs in the head and neckuncommonly involve the larynx ${ }^{2}$. Overall, a 3:1 Female predominance is observed ${ }^{1}$.

The larynx contains two sets of normal paraganglia and paragangliomas. Theyare thought toarise from either the superior or inferior part of laryn $x^{2}$. Thelaryngealparagangliomasfound in the false vocal fold is called glomus laryngicum superior. It is called glomus laryngicum inferior when it found in the paraglottic space close to the cricoid cartilage laterally ${ }^{3}$. Blanchard and Saundersreported the first case of a laryngeal paraganglioma in 1955.

PGLs present as submucosal painless masses that become symptomatic when they exceed a critical size.At this instant thepatient developedhoarsenessof voice followed by dysphagia.

Differential diagnosis of PGLs includes laryngoceles, cysts, lymphoma, lipomas, neural sheath tumours, other neuroendocrinetumours, hemangiopericytoma, and Teflon granulomas ${ }^{3}$. Cervical lymphadenopathy is not found in laryngeal paragangliomas and malignant chance isvery rare. 
Most of these lesions share certain characteristics. They are often well encapsulated, lateral to the quadrangular membrane and rarely have luminal mucosalinvolvement. Therefore, it can be dissected from surrounding tissues easily. Because of these characters their removal becomes easier ${ }^{3}$.

A contrast computed tomography or magnetic resonance imaging scan shows a solid, hypervascular mass and due to flow voidsthat creates a classic "salt-and-pepper" appearance.

Biopsy of these lesions must be trans mucosal.But biopsy of these suspected lesionsthrough direct laryngoscopy need to be avoided. Paragangliomas are highly vascular masses, hencecontrolofbleedingcould be challenging through a laryngoscope.It alsocausesscarringof mucosa onthesurfaceoftheparaganglioma, whichincreases the difficulty of tumour removal throughanyexternalapproach.Similar to other paragangliomas, thediagnosiscan be reached withoutbiopsy ${ }^{3}$. Diagnosis mostlyare dependent on histopathologic examination followed by immunohistochemistry ${ }^{2}$.

Our patient presented with the typical features of PGLs such as voice changes, difficulty of swallowing and associated submucosal supraglottic mass. Microlaryngoscopic transmucosal biopsy of this patient was abandoned because of bleeding.

The recognized treatment of laryngeal paragangliomas is surgery. Transoral laryngoscopic and external Transcervical lateral laryngotomy approaches are the 2 surgical approaches to excise laryngeal paragangliomas. The chance for lateral laryngotomy and possible tracheotomy or prolonged intubation should be included into the consent for the surgery.

Postoperatively thepatientshould be advised to avoidactivities, which increases the supraglotticpressuresuchas balloon blowing or playing wind instruments.Observingthepatient's swallowing forthe first time following surgery ishelpful to determine the degree of dysphagia.

External approach of excision was selected to our patient as it provides greater exposure, better access to laryngeal anatomy and control of bleeding. Patient underwent water soluble contrast study before commencing oralfeeding to exclude aspiration/leak.

\section{Conclusion}

Even though laryngeal paragangliomas is a rare tumourit should be considered as one of the differential diagnoseswhen a patient presented with a submucosal laryngeal mass associated with voice change.

\section{References}

1. Kotsis T., Christoforou P., Vagal Paraganglioma: Surgical Removal with Superior Laryngeal Nerve Preservation. Vascular Specialist International: 2019 (June); 35(2) https://doi.org/10.5758/vsi.2019.35.2.105.PMid:31297361 PMCid:PMC6609016

2. Binesh F., Dadgarnia MH., Khaksar Y., MirvakiliA.. Laryngeal Paraganglioma: A Diagnostic Challenge. Case Report | Iran J Pathol. 2015; 10(4); 322-325

3. Myssiorek D., Treatment of laryngeal paraganglioma. Operative Techniques in Otolaryngology. 2016;27;36-40https://doi.org/10.1016/j.otot.2015.12.002

3. 